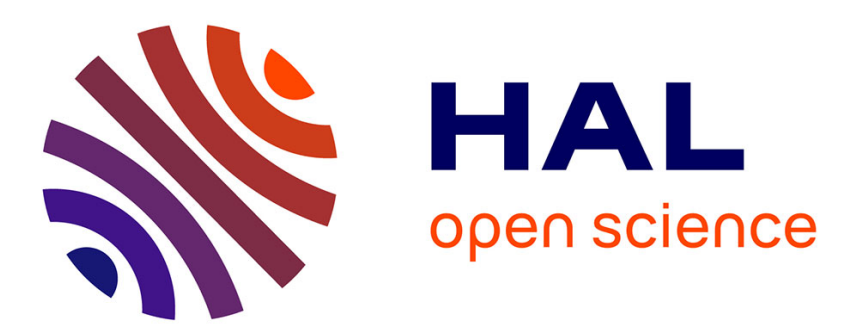

\title{
Mechanical characterization of an electrostrictive polymer for actuation and energy harvesting
}

\author{
A. Eddiai, M. Meddad, Samira Touhtouh, A. Hajjaji, Yahia Boughaleb, D. \\ Guyomar, S. Belkhiat, Bouchta Sahraoui
}

\section{- To cite this version:}

A. Eddiai, M. Meddad, Samira Touhtouh, A. Hajjaji, Yahia Boughaleb, et al.. Mechanical characterization of an electrostrictive polymer for actuation and energy harvesting. Journal of Applied Physics, 2012, 111 (12), Non spécifié. 10.1063/1.4729532 . hal-03344711

HAL Id: hal-03344711

https://univ-angers.hal.science/hal-03344711

Submitted on 15 Sep 2021

HAL is a multi-disciplinary open access archive for the deposit and dissemination of scientific research documents, whether they are published or not. The documents may come from teaching and research institutions in France or abroad, or from public or private research centers.
L'archive ouverte pluridisciplinaire HAL, est destinée au dépôt et à la diffusion de documents scientifiques de niveau recherche, publiés ou non, émanant des établissements d'enseignement et de recherche français ou étrangers, des laboratoires publics ou privés. 


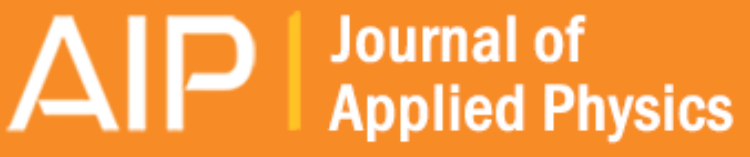

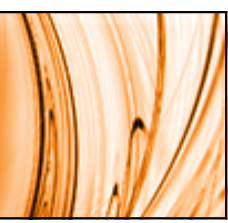

\section{Mechanical characterization of an electrostrictive polymer for actuation and energy}

\section{harvesting}

A. Eddiai, M. Meddad, S. Touhtouh, A. Hajjaji, Y. Boughaleb, D. Guyomar, S. Belkhiat, and B. Sahraoui

Citation: Journal of Applied Physics 111, 124115 (2012); doi: 10.1063/1.4729532

View online: http://dx.doi.org/10.1063/1.4729532

View Table of Contents: http://scitation.aip.org/content/aip/journal/jap/111/12?ver=pdfcov

Published by the AIP Publishing

\section{Articles you may be interested in}

Mechanical energy harvesting via a plasticizer-modified electrostrictive polymer

Appl. Phys. Lett. 108, 042901 (2016); 10.1063/1.4939859

Lumped model of bending electrostrictive transducers for energy harvesting

J. Appl. Phys. 116, 124106 (2014); 10.1063/1.4896185

Preparation of graphene nanoflakes/polymer composites and their performances for actuation and energy harvesting applications

J. Appl. Phys. 111, 104904 (2012); 10.1063/1.4718577

Effects of copper filler sizes on the dielectric properties and the energy harvesting capability of nonpercolated polyurethane composites

J. Appl. Phys. 109, 024104 (2011); 10.1063/1.3534000

Evaluation of energy harvesting performance of electrostrictive polymer and carbon-filled terpolymer composites J. Appl. Phys. 108, 034901 (2010); 10.1063/1.3456084

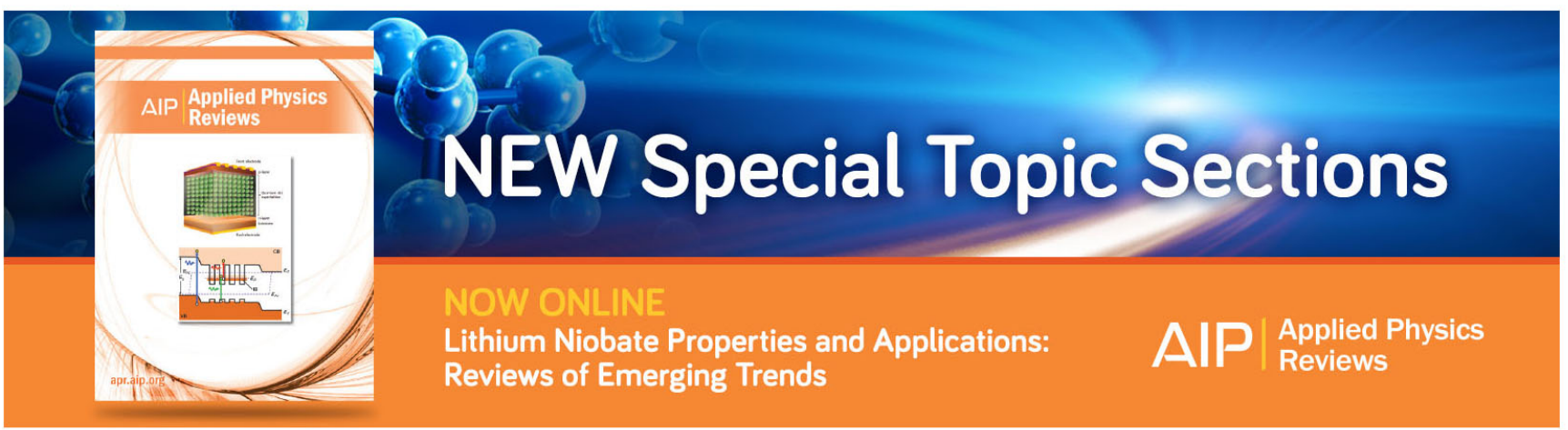




\title{
Mechanical characterization of an electrostrictive polymer for actuation and energy harvesting
}

\author{
A. Eddiai, ${ }^{1,2}$ M. Meddad,,${ }^{2,4}$ S. Touhtouh, ${ }^{1}$ A. Hajjaji, ${ }^{3}$ Y. Boughaleb,,${ }^{1,5}$ D. Guyomar, ${ }^{2}$ \\ S. Belkhiat ${ }^{4}$ and B. Sahraoui ${ }^{6}$ \\ ${ }^{1}$ Université Chouaib Doukkali, Faculté des Sciences, El Jadida, Morocco \\ ${ }^{2}$ Laboratoire de Génie Electrique et Ferroélectricité (LGEF), INSA LYON, Bat. Gustave Ferrie, \\ 69621 Villeurbanne Cedex, France \\ ${ }^{3}$ Université Chouaib Doukkali, Ecole Nationale des Sciences Appliquées, EL Jadida, Morocco \\ ${ }^{4}$ DAC HR Laboratory, Université Ferhat Abbas, 19000 Sétif, Algeria \\ ${ }^{5}$ Hassan II Academy of Sciences and Technology, Rabat, Morocco \\ ${ }^{6}$ LUNAM Université, Université d' Angers, CNRS UMR 6200, Laboratoire MOLTECH-Anjou, \\ 2 bd Lavoisier, 49045 ANGERS Cedex, France
}

(Received 7 October 2011; accepted 15 May 2012; published online 28 June 2012)

\begin{abstract}
Electroactive polymers have been widely used as smart material for actuators in recent years. Electromechanical applications are currently focused on energy harvesting and actuation, including the development of wireless portable electronic equipment autonomous and specific actuators such as artificial muscles. The problem to be solved is to make its devices the most efficient, as possible in terms of harvested energy and action. These two criteria are controlled by the permittivity of the electrostrictive polymer used, the Young's modulus, and their dependence on frequency and level of stress. In the present paper, we presented a model describing the mechanical behaviour of electrostrictive polymers with taking into account the mechanical losses. Young's modulus follows a linear function of strain and stress. However, when the elongation becomes higher, the data obtained from this strain linear trend and significant hysteresis loops appear the reflections on the existence of mechanical losses. In this work, to provide the analysis of the experimental observations, we utilized a theoretical model in order to define a constitutive law implying a representative relationship between stress and strain. After detailing this theoretical model, the simulation results are compared with experimental ones. The results show that hysteresis loss increases with the increase of frequency and strain amplitude. The model used here is in good agreement with the experimental results. (C) 2012 American Institute of Physics.
\end{abstract}

[http://dx.doi.org/10.1063/1.4729532]

\section{INTRODUCTION}

Electroactive polymers (EAPs), as a category of polymeric materials that deform under electrical stimuli, are emerging as promising alternatives to existing materials for actuation and sensing applications. In contrast to traditional actuator materials (e.g., piezoelectric ceramics) which are known for their high load capacity but small strain, electroactive polymers are characterized by their softness, flexibility, and the consequent large-strain capability, as reviewed by Bar-Cohen and Zhang. ${ }^{1}$ The properties of electroactive polymers resemble those of natural biological muscles, and are expected to provide biomimetic opportunities for industry and bring impact to various areas that include robotics, biomedical devices, and energy harvesting. ${ }^{2-6}$ The type of electroactive material known as electrostrictive polymer has shown considerable promise for a variety of actuator applications ${ }^{7-9}$ and may be well suited for harvesting energy from vibration sources, such as human motion. ${ }^{10,11}$

Electrostrictive polymers exhibit very attractive characteristics, and as a result, they have been widely studied either for the purpose of understanding the electrostriction phenomenon ${ }^{12-14}$ or in view of practical applications. ${ }^{15,16}$
The development of new materials with large strains results in several applications that take advantage of the electrostrictive materials as actuators or as tunable transducers. ${ }^{17,18}$ The electrostrictors have an advantage over actuator materials with low hysteresis of the strain field response, no remnant strain, reduced aging and creep effects, a high response speed, and substantial strains at realizable electric fields.

Previous studies conducted by Eury et al..$^{19}$ and by Guillot and Balizer ${ }^{20}$ have shown that the coefficient of electrostriction is proportional to the permittivity and Young's modulus. This dependence clearly demonstrates that increased permittivity material causes an increase in performance of electrostrictive polymers and dielectric elastomers. It is therefore essential to develop methods capable of increasing the dielectric properties while ensuring an optimal Young's modulus to maintain the flexible polymers with a minimum mechanical loss. Young's modulus follows a linear function of strain and stress. The reversible phenomenon, which refers to the absence of energy dissipated during a cycle, consists of loading followed by the same unloading paths of loading and unloading. In other words, the mechanical energy absorbed by the resilient material to deform is fully stored, then restored when the stress is removed. 
Young's modulus follows a linear function of strain and stress. However, when the elongation becomes higher, the deformation curve is derived from the linear trend and a significant hysteresis loop appears reflecting the existence of mechanical losses.

Many constitutive models have been proposed to reproduce the complex mechanical behaviour of EAP, such as hyper-elasticity ${ }^{21,22}$ and viscoelasticity. ${ }^{23-25}$ Tomita et al. further proposed a visco-hyper elastic 8-chain network model that incorporates a nonlinear dashpot with Langevin springs. ${ }^{26}$ In this work, we proposed a simple model in order to describe the mechanical losses in electrostrictive polymers. These different testing frequency and strain amplitude have to highlight the intrinsic parameters of the material to optimize, namely Young's modulus, and also to know the mechanical losses in a frequency range and to demonstrate the interest of this model for improving properties on actuating and energy harvesting. The theory offered here is detailed, and then the simulation results are compared with experimental ones.

\section{EXPERIMENTAL SETUP}

The detailed experimental setup has been reported elsewhere. ${ }^{7,27}$ Therefore, only the essential work-up is presented here.

The polyurethane (PU) granules were first dissolved in $\mathrm{N}, \mathrm{N}$-dimethylformamide under mixing at $80^{\circ} \mathrm{C}$ until the PU solution became homogeneous. Carbonblack nanopowder ( $1 \mathrm{wt} . \% \mathrm{C}$ with an average particle size is less than $50 \mathrm{~nm}$, Aldrich 633100) was added to the solution and stirred at $80^{\circ} \mathrm{C}$ for $60 \mathrm{~min}$ until the mixture became homogeneous and had a suitable viscosity. After deposition, the film was dried at $60^{\circ} \mathrm{C}$ for $24 \mathrm{~h}$. After removing from the glass plate using alcohol, the films were annealed at $130^{\circ} \mathrm{C}$ for $3 \mathrm{~h}$, for a complete elimination of the solvent. These specimens with carbon were denoted simply "composite" samples. A certain variation in thickness, between 20 and $120 \mu \mathrm{m}$, was prepared.

The process presented below is described for the preparation of a composite using polyurethane, but it can be generalized other types of matrices.

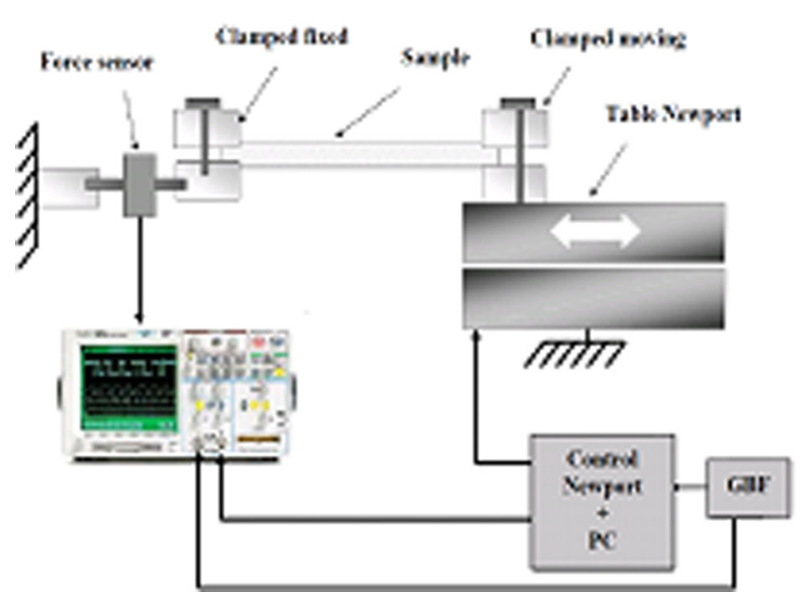

\section{BASIC MATERIALS}

Depending on the equipment, the different modes of solicitation may be used (tensile, shear, pure bending, etc.). Monitoring can be done either by fixing the applied force and measuring the deformation or with straining imposed by working and measuring the force.

In our case, the tensile tests were chosen for ease of implementation. These measurements are made using the table with one degree of freedom Newport. Figure 1 illustrates the operating principle. The test sample is clamped between two jaws, one of the mobiles is placed as connected to the table with one degree of freedom, the other one is fixed as connected to the transducer. Sheets of specimen between 20 and $100 \mu \mathrm{m}$ in thickness were cut into rectangular, $9.5 \mathrm{~mm}$ with width and $25 \mathrm{~mm}$ with length (Figure 1). Newport table is controlled using a function generator connected to the controller. The signals delivered by the force sensor and displacement are then displayed on an oscilloscope. It is possible to obtain a wide range of strain over a large frequency band.

\section{THEORETICAL MODEL}

This study allows us to present a model of hysteretic behaviour in electrostrictive polymers and to determine the relationship between the strain $S$ and stress $T$ by introducing the mechanical losses. A great number of laboratory tests on polymers shows that the cyclic stress-strain curves are highly nonlinear and constitute a closed hysteresis loops. The results of these tests seem to indicate that the damping properties are especially of hysteretic type, and not viscous as those corresponding to the Kelvin-Voigt model. ${ }^{28}$

The generalized Hooke model (also known as the spring model) is the simplest model for describing the variation of the deformation $S$ of a sample with the mechanical stress $T$. The model is linear, predicting that the displacement $U$ applied to the sample is proportional to the force $F$ detected by force sensor.

The mathematical representation of this behaviour is given with the following equation:

$$
T=Y S .
$$

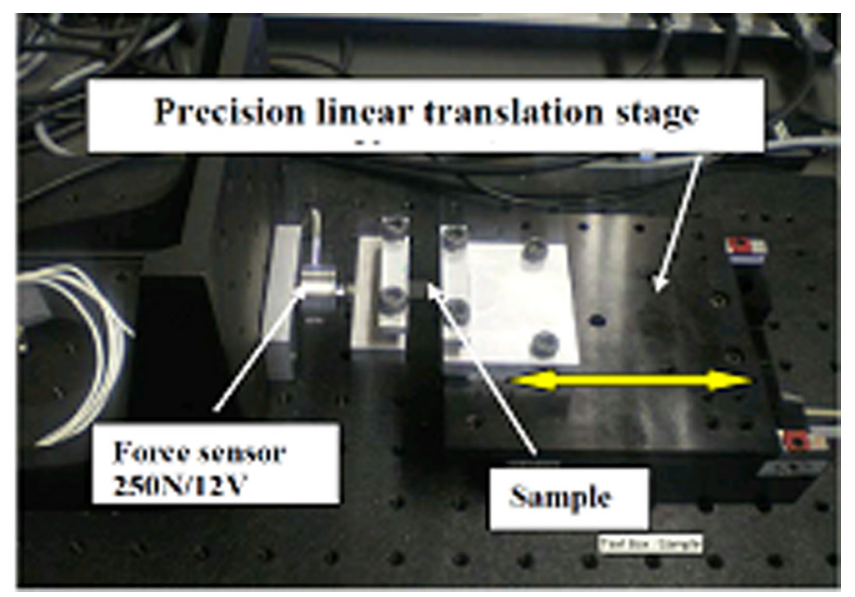

FIG. 1. Schematic illustration and photograph of the experimental setup for measuring the stress-strain behaviour in the electrostrictive polymers. 
The previous model has allowed us to understand the phenomenon of non-linearity observed in the curves of stress as a function of deformation. By analogy, the application of a displacement on our material may be equivalent to a spring in series with a damper as shown in Figure 2, the spring characteristic of the polymer film and the damper allow us to describe the mechanical losses in the film, where (1) is the damper, (2) is the spring, and (3) is the direction of longitudinal displacement.

The basic principle is to introduce mechanical losses to the Eq. (1) by the variation of Young's modulus versus times, and then the expression of stress becomes

$$
T(t)=Y_{0} h(t) \otimes S(t) .
$$

Here, $\otimes$ corresponds to the convolution operation.

Where $Y_{0}$ is the Young's modulus of the electrostrictive polymer and $h(t)$ is a function to introduce mechanical losses through a mechanical characteristic time $\tau_{m e c}$, and it is expressed as

$$
h(t)=e^{\left(-\frac{t}{\tau_{\text {mec }}}\right)} .
$$

With

$$
T(t)=\frac{F(t)}{e L}
$$

and

$$
S(t)=\frac{U(t)}{l},
$$

where e is the thickness, $l$ is the length, and $L$ is the width.

So the final equation of force harvested as a function of imposed displacement becomes as follows:

$$
F(t)=\left(\frac{e L Y_{0}}{l}\right)\left(e^{\left(-\frac{t}{\tau_{\text {mec }}}\right)} \otimes U(t)\right) .
$$

In this experiment, a sinusoidal displacement which can be experimentally implemented and harvested sinusoidal signal strength (Fig. 1) was used. This displacement is given by

$$
U(t)=U_{d c}+U_{a c} \sin (\omega t),
$$

where $U_{d c}, \omega$, and $U_{a c}$ correspond to the pre-displacement, the pulsation of the mechanical excitation, and the amplitude of displacement, respectively.

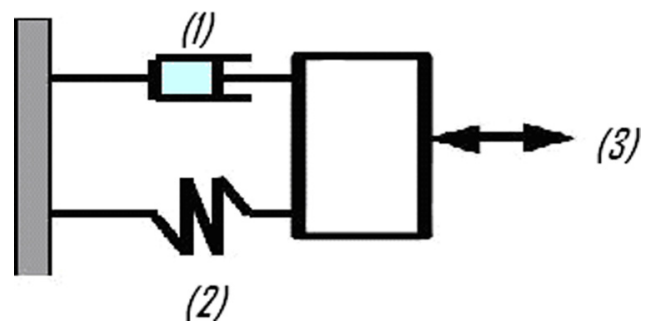

FIG. 2. Equivalent structure of the polymer.

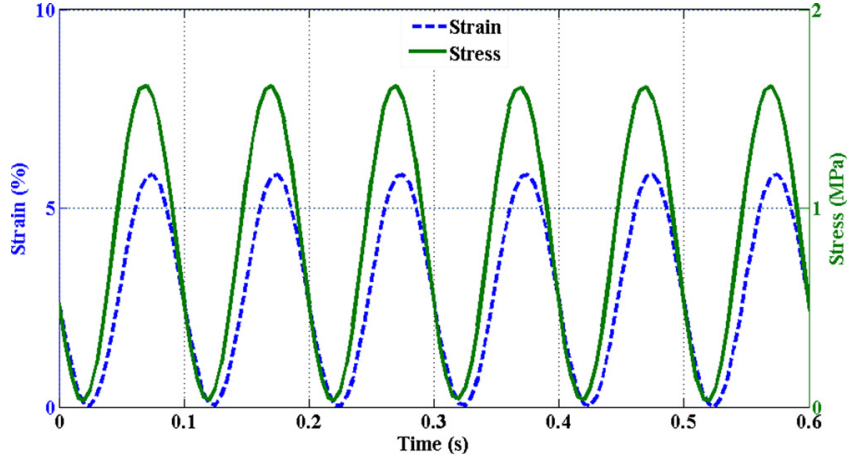

FIG. 3. The strain (S) and stress (T) versus time.

Fig. 3 depicts $S$ and $T$ versus time for P(VDF-TrFECFE) film with a $78 \mu \mathrm{m}$ thickness, a $70 \mathrm{mVpp}$ amplitude of displacement, and a $10 \mathrm{~Hz}$ frequency.

\section{RESULTS AND DISCUSSION}

The stress-strain behaviour, in which contains the uniaxial tests, of polyurethane and P(VDF-TrFE-CFE) with carbon black powders $(1 \mathrm{wt}$. \% C) was examined using the techniques described in Sec. III. The specimen was stretched with different amplitude displacements 35, 70, and $100 \mathrm{mVpp}$ in a quasi-static frequency range $(100 \mathrm{mHz}$ up to $10 \mathrm{~Hz})$. Figure 4 shows the comparison between the model and the experimental result for a sample type PU $1 \% \mathrm{C}$ at displacement amplitude of $100 \mathrm{mVpp}$, a frequency of $10 \mathrm{~Hz}$ and a thickness of $57 \mu \mathrm{m}$. An excellent agreement has been found between the proposed modelling and the experimental data measured for the electrostrictive polymers. The behaviour of the material has a clear hysteresis curve. This suggests that the character of nonlinear strain with stress is due to the existence of mechanical losses within the material.

These losses become a form of energy dissipated within the material, so using this model, we can minimize these losses by reducing the surface of the stress-strain hysteresis by adjusting the amplitude of the applied deformation and frequency.

Figure 5 shows the axial traction stress-strain behaviour of a sample PU $1 \% \mathrm{C}$ with thickness of $90 \mu \mathrm{m}$ and $1 \mathrm{~Hz}$ frequency (Fig. 5(a)) and P(VDF-TrFE-CFE) $1 \% \mathrm{C}$ with a thickness of $78 \mu \mathrm{m}$ and frequency $0.1 \mathrm{~Hz}$ (Fig. 5(b)). These

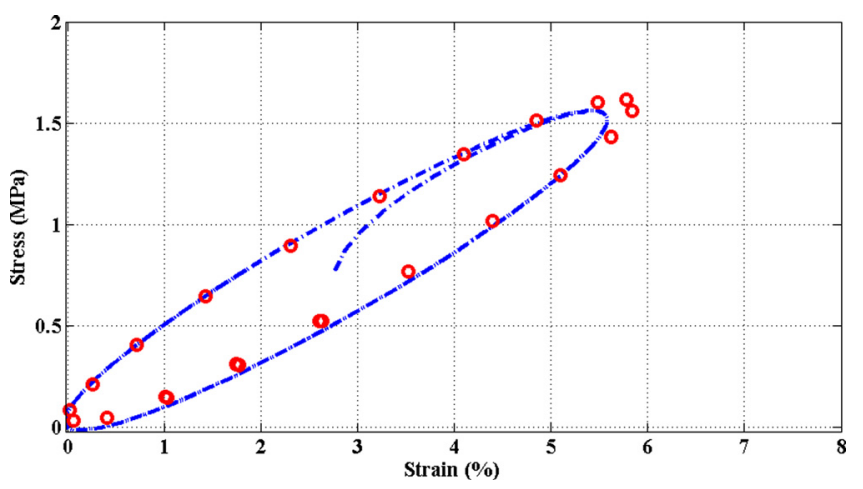

FIG. 4. Strain-stress curve for PU $1 \%$ C. 

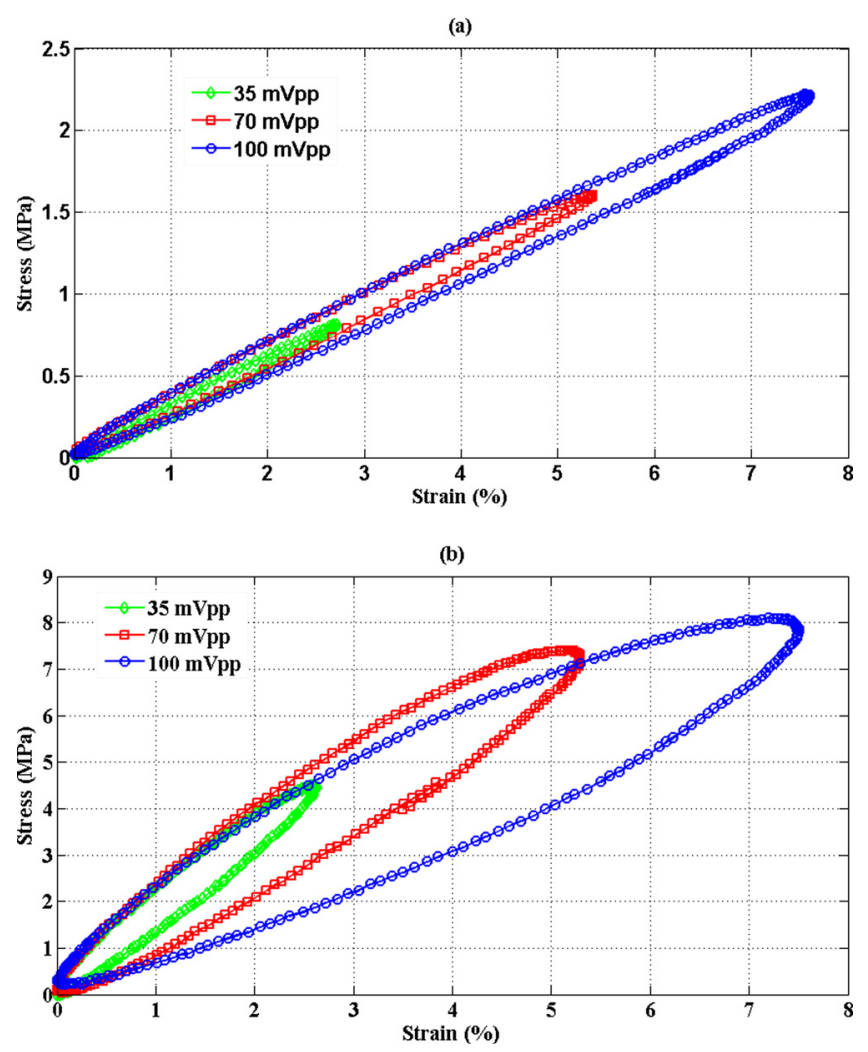

FIG. 5. Strain-stress curve for (a) PU $1 \% \mathrm{C}$ and (b) P(VDF-TrFE-CFE) $1 \% \mathrm{C}$.

results clearly show that the mechanical loss, i.e., the Young's modulus of the materials, varies with time and grows by increasing the amplitude of displacement, it means that as the amplitude of displacement becomes greater the loss mechanism introduced also becomes greater.

On the other side, the variation in the magnitude of Young's modulus depends on type of material. For PU $1 \%$ $\mathrm{C}$, this variation is unchanged from the increased hysteresis. So in this case, the magnitude of Young's modulus remains almost unchanged (Table I), but the increase in the hysteresis loop corresponds to the energy dissipated in each cycle.

But in the case of $\mathrm{P}(\mathrm{VDF}-\mathrm{TrFE}-\mathrm{CFE}) \mathrm{C} 1 \%$, we observed that the increase in the hysteresis loop with the variation of the displacement amplitude, resulted in a decreased in the amplitude of the module Young (Table I), can be explained by the nature of our polymer (thermoplastic), this material has a high strain rate to obtain a peak (maximum stress) which coincides with the constriction; locally in a band, the deformation can reach a high value (100\%) and a significant softening of the polymer occurs. As a result, the

TABLE I. The amplitude of Young's modulus for PU $1 \% \mathrm{C}$ and P(VDFTrFE-CFE) $1 \% \mathrm{C}$ at different amplitude of displacement.

\begin{tabular}{lcc}
\hline \hline & \multicolumn{2}{c}{ Amplitude of Young's modulus (MPa) } \\
\cline { 2 - 3 } Materials & PU 1\% C at 1 Hz & P(VDF-TrFE-CFE) $1 \% \mathrm{C}$ at $0.1 \mathrm{~Hz}$ \\
\hline $35 \mathrm{mVpp}$ & 30.02 & 156 \\
$70 \mathrm{mVpp}$ & 30.18 & 148 \\
$100 \mathrm{mVpp}$ & 29.22 & 121 \\
\hline \hline
\end{tabular}

stress required to maintain the constant strain rate decreases (plasticity). ${ }^{29,30}$

It appears from Figure 5 that the Young's modulus plays an important role in the actuating response of polymer films. Though a relative permittivity is important in the case of films of $\mathrm{P}(\mathrm{VDF}-\mathrm{TrFE}-\mathrm{CFE})$, the deformation is not as great as anticipated in the first comment. This reflects the fact that the elastic constants between the two types of matrix are very large (40 MPa and $220 \mathrm{MPa}$ for the PU for the $\mathrm{P}(\mathrm{VDF}-\mathrm{TrFE}-\mathrm{CFE})$ ). Such data are crucial because they help to define the optimal operating range in which it is possible to use polymers for energy harvesting and actuation at a given temperature.

To obtain Figure 6, we used two different samples with the same amplitude of displacement $100 \mathrm{mVpp}$ : (a) one is a $\mathrm{P}(\mathrm{VDF}-\mathrm{TrFE}-\mathrm{CFE}) \% \mathrm{C}$ with a thickness of $49 \mu \mathrm{m}$, and (b) the other one is a PU $1 \% \mathrm{C}$ with a thickness of $138 \mu \mathrm{m}$. Concerning the variation of hysteresis loop, the stress-strain is given as a function of frequency (quasi-static field). Figure 6 shows clearly that the area of the hysteresis loop remains almost unchanged with the change of frequency; therefore, when we increase the frequency, the slope of the curve increases which means the increase of the magnitude of Young's modulus. For frequencies below $20 \mathrm{~Hz}$, it is interesting to note that the mechanical losses in the polymer are low. Against them to become more important later with an increase in Young's modulus, effective for the frequency band where the maximum loss occurs, the effectiveness of our polymers, such as energy harvesting, will not be optimal as much energy mechanics will be dissipated as losses

(a)

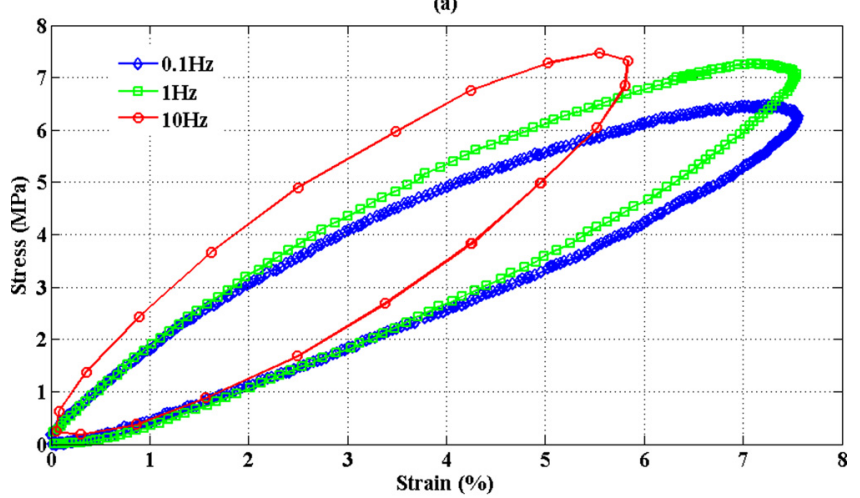

(b)

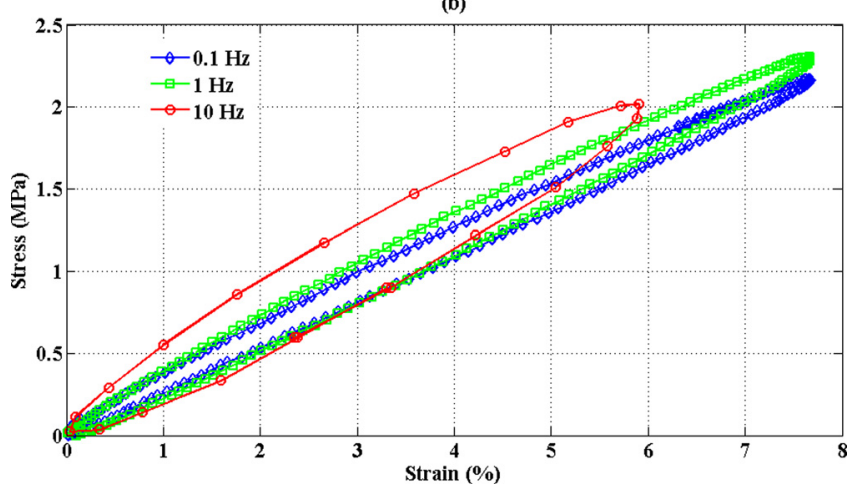

FIG. 6. Strain-stress curve for (a) P(VDF-TrFE-CFE) $1 \% \mathrm{C}$ and (b) PU $1 \% \mathrm{C}$. 
(heat). This maximum occurring in high frequencies is not a primary constraint to target applications, which the most of mechanical vibrations occur at lower frequencies.

We discussed the hysteresis loss due to the nonlinear behavior between the strain and mechanical stress given by Eq. (2). It is noted that for low amplitudes of deformation, the hysteresis loop is very low, i.e., one can neglect the mechanical losses. On the other side, for high amplitudes of deformation, the cycle becomes wider, which means that mechanical energy dissipation is important. But the change in frequency only affects the amplitude of mechanical parameters $(Y)$, which conserves the mechanical energy generated by the polymer.

Utilizing this model, one can clearly see the dependence of mechanical losses by examining the change in strain amplitude and frequency. So, the mechanical energy dissipated in electroactive polymers could be minimized.

\section{CONCLUSION}

This work has reported a simple conventional method to describe the mechanical behaviour of electrostrictive polymers by taking into account the losses. These losses are referred to a function $h(t)$ by convolution with displacement and this function relates to the nonlinear behavior between the deformation and mechanical stress. Simulation results obtained here are in good agreement with experimental ones. And it can be concluded that the mechanical losses have a strong relationship with the strain amplitude. It is shown that the hysteresis loss increases with an increase in dynamic strain amplitude, i.e., an increase of mechanical energy dissipated in the material. The engine as energy, responsible for elasticity true, results in the verification of Hooke's law at low deformation, it is important to keep in mind that Hooke's law is valid at low deformation regardless of the complexity of the stress field applied.

But depending on the influence of frequency, it has a strong dependence on the magnitude of Young's modulus, as the frequency increases, the magnitude of Young's modulus increases. So to minimize the mechanical losses and increases on the magnitude of Young's modulus, one has to control two parameters (strain and frequency).

${ }^{1}$ Y. Bar-Cohen and Q. Zhang, MRS Bull. 33, 173 (2008).

${ }^{2}$ Y. Bar-Cohen, J. Spacecr. Rockets 39, 822 (2002).

${ }^{3}$ Y. Bar-Cohen, ed. (SPIE Optical Engineering Press, 2001), PM136, 687.

${ }^{4}$ X. Q. Zhang, C. Lowe, M. Wissler, B. Jahne, and G. Kovacs, Adv. Eng. Mater. 7, 361 (2005).

${ }^{5}$ A. Wingert, M. D. Lichter, and S. Dubowsky, IEEE/ASME Trans. Mechatron. 11, 448 (2006).

${ }^{6}$ Y. Sugiyama and S. Hirai, Int. J. Robot. Res. 25, 603 (2006).

${ }^{7}$ B. Guiffard, L. Seveyrat, G. Sebald, and D. Guyomar, J. Phys. D: Appl. Phys. 39, 3053 (2006).

${ }^{8}$ L. Petit, B. Guiffard, L. Seveyrat, and D. Guyomar, Sens. Actuators, A 148, 105 (2008)

${ }^{9}$ B. Guiffard, D. Guyomar, L. Seveyrat, Y. Chowanek, M. Bechelany, D. Cornu, and P. Miele, J. Phys. D: Appl. Phys. 42, 055503 (2009).

${ }^{10}$ L. Lebrun, D. Guyomar, B. Guiffard, P.-J. Cottinet, and C. Putson, Sens. Actuators, A 153, 251 (2009).

${ }^{11}$ D. Guyomar, L. Lebrun, C. Putson, P.-J. Cottinet, B. Guiffard, and S. Muensit, J. Appl. Phys. 106, 8979 (2009).

${ }^{12}$ R. Yimnirun, S. Eury, V. Sundar, P. J. Moses, and R. E. Newnham, in IEEE Conference on Electrical Insulation and Dielectric Phenomena (1999), 1, 338.

${ }^{13}$ F. M. Guillot and E. Balizer, J. Appl. Polym. Sci. 89, 399 (2003).

${ }^{14}$ J. Su, Q. M. Zhang, P. Wang, A. G. Macdiarmid, and K. J. Wynne, Polym. Adv. Technol. 9, 317 (1998).

${ }^{15}$ J. M. Herbert, Ferroelectr. Transducers Sens. 3, 437 (1982).

${ }^{16}$ Y. Bar-Cohen, in Proceedings of the 42nd A.I.A.A Structures, Structural Dynamics and Material Conference (SDM), (2001), 350, 1.

${ }^{17}$ L. E. Cross, J. Appl. Phys. 34, 2525 (1995).

${ }^{18}$ V. Sundar and R. E. Newnham, Mater. Res. Bull. 31, 545 (1996).

${ }^{19}$ S. Eury, R. Yimnirun, V. Sundar, P. J. Moses, S.-J. Jang, and R. E. Newnham, Mater. Chem. Phys. 61, 18 (1999).

${ }^{20}$ F. M. Guillot and E. Balizer, J. Appl. Polym. Sci. 89, 399 (2002).

${ }^{21}$ M. M. Attard and G. W. Hunt, Int. J. Solids Struct. 41, 5327 (2004).

${ }^{22}$ E. M. Arruda and M. C. Boyce, J. Mech. Phys. Solids 41, 389 (1993).

${ }^{23}$ A. D. Drozdov and A. Dorfmann, Arch. Appl. Mech. 72, 651 (2003).

${ }^{24}$ J. D. Wu and M. L. Kenneth, Mech. Time-Depend. Mater. 4, 293 (2000).

${ }^{25}$ J. S. Bergström and M. C. Boyce, J. Mech. Phys. Solids 46, 931 (1998).

${ }^{26}$ Y. Tomita, K. Azuma, and M. Naito, Int. J. Mech. Sci. 50, 856 (2008).

${ }^{27}$ K. Yuse, B. Guiffard, R. Belouadah, L. Petit, L. Seveyrat, and D. Guyomar, Fron. Mech. Eng. 4, 350 (2009).

${ }^{28}$ D. Bratosin and T. Sireteanu, Proc. Rom. Acad., Ser. A 3 (2002).

${ }^{29}$ T. Xu and G. Li, Polymer 52, 4571-4580 (2011).

${ }^{30}$ T. Xu and G. Li, Mater. Sci. Eng. A-Struct. 582, 6804-11 (2011). 